\title{
Influence of Spleen Size and Portal Pressure on Erythrocyte Sequestration *
}

\author{
R. Thomas Holzbach, Reginald A. Shipley, Richard E. Clark, and \\ Ethel Buchwald Chudzik \\ (From the Section of Gastroenterology and the Radioisotope Service, Veterans Administration \\ Hospital, and the Department of Medicine, Western Reserve University, \\ School of Medicine, Cleveland, Ohio)
}

That a hemolytic process is one of the potential causes of anemia in cirrhosis of the liver has been well established by repeated demonstrations of decreased red cell survival time in a large proportion of patients (1-7). Shortened survival has been noted, not only with autologous cells, but also with transfused normal donor cells $(1,2)$. This would clearly establish the existence of an extracorpuscular factor. Moreover, Jandl (2) has pointed out that the exponential contour of disappearance curves observed in patients with cirrhosis suggests random fractional removal of cells by an organ such as the spleen. This of course is consistent with the widely accepted notion that the congestive splenomegaly of cirrhosis causes "hypersplenism."

In previous studies employing thermally damaged $\mathrm{Cr}^{51}$-labeled red cells to assess the size of the spleen by a scanning procedure, both we (8) and Wagner and co-workers (9) found that the cells tended to disappear from circulating blood more rapidly in patients with cirrhosis than in control subjects. The present investigation was conducted in order that the rate of removal of thermally damaged cells might be measured definitively by analysis either of blood disappearance curves or of curves obtained by continuous recording of activity through an external probe placed over the spleen. It was expected that a sequestration function could be assessed in patients with cirrhosis and other disorders affecting the spleen if the corpuscular variable were minimized by introducing labeled red cells that had been subjected to standardized thermal damage. At the same time the size of the spleen could be estimated by the scanning procedure previously described (8).

* Submitted for publication October 28, 1963 ; accepted January 30, 1964.
A measurement of spleen size along with measurements of portal pressure in patients with cirrhosis would allow correlations to be sought that might favor either size or congestive stasis as the principal cause of accelerated disappearance of erythrocytes.

\section{Methods}

Controls (15 patients). These were hospitalized male patients ranging in age from 32 to 60 years. Most had entered for treatment of active but uncomplicated peptic ulcer. They were carefully screened to exclude the presence of existing or previous liver disease, abnormalities of liver function, and other known causes of "hypersplenism."

Cirrhosis (19 patients). These were hospitalized male patients, ages 33 to 66 years, in whom the diagnosis of cirrhosis had been made on the basis of clinical criteria including the following: history of alcoholism, various physical stigmata such as cutaneous spiders, hepatomegaly, jaundice, esophageal varices, ascites, and derangement of chemical liver function tests. Four had hemoglobin values below $11 \mathrm{~g}$, and 7 below $12 \mathrm{~g}$ at the time of admission.

Miscellaneous disorders (5 patients). A small nonhomogeneous group of patients with splenomegaly, or disorders which lead to splenomegaly, was also studied. This group is characterized in Table II.

The method of $\mathrm{Cr}^{51}$ labeling and heat treatment of autologous erythrocytes before intravenous injection was the same as previously described (8). Briefly stated, it consisted of incubation of whole blood with radiochromate at room temperature followed by incubation of the washed cells in physiologic saline at $49.0 \pm 0.1^{\circ} \mathrm{C}$ for exactly 60 minutes. The amount of radiochromium actually injected in this study ranged from 200 to $250 \mu \mathrm{c}$. Approximately 1 minute was required for the injection. In 27 patients, disappearance curves of radioactivity from whole blood were obtained by observations on venous samples collected, respectively, at approximately $2,5,10$, $15,20,30,45$, and 60 minutes after injection, again at either 2 or 4 hours, and usually at 24 hours. In 11 of these 24 patients serum radioactivity also was determined to permit construction of a curve for serum and erythrocytes separately. 
Continuous recording of radioactivity over the splenic area was obtained for 1 hour after injection with the probe placed laterally in contact with the skin, and with the patient reclining in the supine position. In 17 subjects a similar recording was made from a second detector over the liver anteriorly. A rate meter, stripchart recorder, and a sodium iodide crystal $1 \frac{1}{2}$ inches wide by 1 inch thick fitted with a $1 \frac{1}{2}-\times 1 \frac{1}{2}$-inch collimator were used as the detection system. Spleen scanning was performed within 3 hours after injection with the patient recumbent and with the left lateral aspect exposed to a conventional scanner. The scanner utilized a 19-hole focusing collimator, an integral mounted sodium iodide crystal 3 inches wide by 1 inch thick, and a rate meter with discriminator setting at $0.25 \mathrm{Mev}$. Splenic scan area was measured with a planimeter.

Portal venous pressure measurements were obtained indirectly by splenic pulp manometry, as modified from the method of Atkinson and Sherlock (10), with a $10-\mathrm{cm}$ base line. The mean value of two or three observations was recorded.

Osmotic fragility of erythrocytes was determined by a standardized adaptation of the method of Parpart and co-workers (11). Serial concentrations ranged from 0.26 to $1.2 \%$ of saline in phosphate buffer. Readings were made on a Klett-Summerson (model no. 7002) photoelectric colorimeter. Fragility was expressed as the dilution of saline where beginning hemolysis was unequivocal. Specifically, it was the intercept of the straight midportion of the curve on the abscissal scale of saline concentration. The ordinate scale was percentage of hemolysis.

\section{Results}

Blood disappearance. Separate mean curves of disappearance for whole blood, serum, and erythrocytes are shown in Figure 1. The loss of activity from whole blood is very rapid. If the 2-minute sample is taken as an initial reference point, the percentage remaining at one-half hour is approximately $18 \%$. At 1 hour it is $12 \%$, and at 4 hours, $2 \%$. The early portion of the curve is almost completely dominated by the decline in activity of the red cell component. After approximately 1 hour, however, the activity in erythrocytes has fallen to a point where the relative contribution of serum is appreciable. By 4 hours the red cell component amounts to only $1 \%$ of that which had existed at 2 minutes. The concentration in cells at this time and henceforth is surpassed by that of serum. In the period beyond 4 hours a slow loss from the erythrocyte compartment suggests the presence of a minor population of cells that have escaped serious thermal damage.

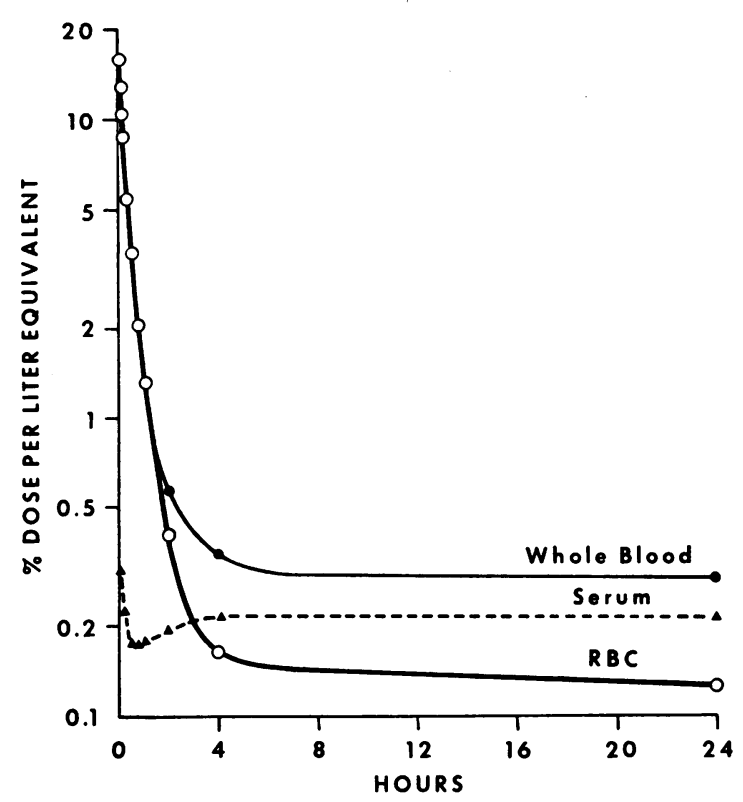

Fig. 1. Disappearance curves, mean of eight conTROL SUBJECTS. Activity for whole blood is expressed as percentage of dose per liter obtained by direct count; that for serum and cells as percentage of dose per liter of whole blood equivalent obtained by direct serum count. The serum activity is corrected to liter of whole blood equivalent by the formula: (\% dose per $\mathrm{L}$ serum) (1hematocrit). This subtracted from percentage of dose per liter of whole blood gives the activity for cells present in $1 \mathrm{~L}$ of blood. The mean hematocrit was 0.47 .

The trace of activity in the 2-minute sample of serum is undoubtedly from chromium lost from cells directly into plasma immediately after injection. The transient decline during the ensuing 15 minutes can probably be ascribed to excretory loss, whereas the slow rise thereafter suggests splenic discharge consequent to sequestration and dissolution of trapped cells. The succeeding plateau might be produced by a state of equilibrium between entry into plasma and excretion therefrom.

A preliminary analysis of data suggested that the mean curve of disappearance of labeled heated cells from blood was more rapid in patients with cirrhosis than in control subjects. The difference between the two curves was particularly noticeable in the segment beyond 10 minutes. In the group with cirrhosis the level of activity from 10 to 60 minutes was below that of the normal mean curve. The difference, nevertheless, was small, and statistical significance could not be established. But when the patients with a large spleen $\left(>90 \mathrm{~cm}^{2}\right)$ 
were separated into a subgroup and compared to subjects from both groups with spleens that scanned less than $90 \mathrm{~cm}^{2}$, i.e., normal-sized spleens, a distinct difference in the curves was apparent (Figure 2). That the difference in position of the curves after 15 minutes was significant was established by constructing a mean curve of all observed points beyond this time, counting the two separate categories of points above or below the line, and calculating Chi square by a fourfold table. The value of $p$ was less than 0.01 . A1though these particular curves were derived from whole blood rather than separated cells, a variable serum component would introduce insignificant error during the first hour. The lower position of the mean curve of the group with splenomegaly suggests that cells had been removed more rapidly than in controls. Although a larger blood volume or increased splenic reservoir of red cells

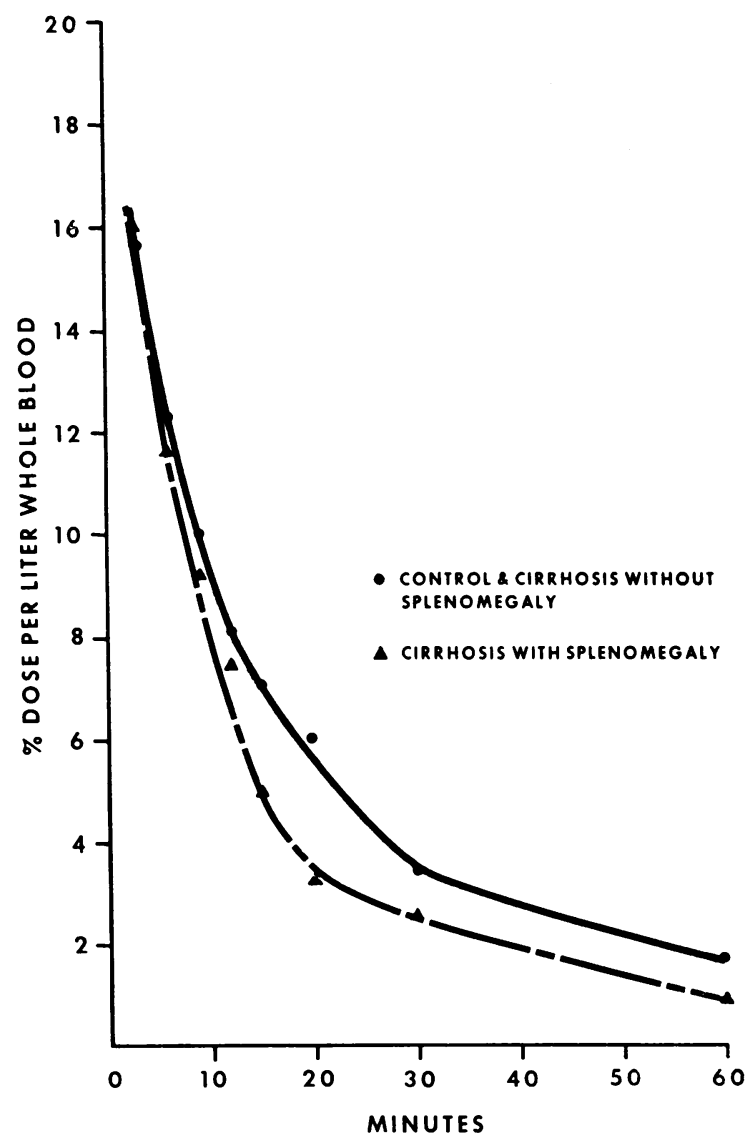

Fig. 2. Mean disappearance curves, large SPleEN vS. NORMAL SPLEEN. Nine patients with splenomegaly, 15 with normal spleen. might be proposed as an explanation, this seems unlikely in light of the large magnitude of the relative difference in concentration at 1 hour (ratio 2 to 1$)$.

Because the characteristic blood disappearance curve is a complex exponential, a quantitative intercomparison of curves cannot be made until component slopes are determined. All curves, when subjected to conventional curve analysis, have yielded three simple exponential components as shown in the mean curve for 8 control subjects in Figure 3. The curve is dominated during the first hour by the rapid component with the slope $\lambda_{1}$. A possible source of the late slope $\left(\lambda_{3}\right)$ has already been mentioned. Perhaps the intermediate slope $\left(\lambda_{2}\right)$ represents cells, undoubtedly more heterogeneous than an apparent single slope would imply, which have received intermediate damage. In any event $\lambda_{1}$, the slope of the early component, may be looked upon as the dominant rate constant for removal of the preponderant mass of seriously altered cells. It is a measure of the fraction of cells sequestered per unit time in all recipient organs as a group. In practical application, however, this rate constant has the serious disadvantage of being subject to a rather large error of estimate. It is derived bý sequential subtraction of two components of a curve that cannot be delineated with reasonable certainty beyond 1 hour because of the paucity of observed points after this time. A more accurate measure of sequestration rate would be desirable.

Rate of sequestration as measured by body surface recording. With a counter in constant position over the spleen it was possible to obtain a continuous record of activity in the interval during which most of the labeled cells were removed from the blood. Such a curve is shown in Figure 4. It is more than $90 \%$ toward plateau at $\frac{1}{2}$ hour and essentially at plateau by 1 hour. The plateau, of course, is not absolute because radioactivity is continually leaving the spleen in the form of disrupted cells. This rate of loss, nevertheless, is so slow in comparison with uptake (8) that for purposes of analysis of the uptake phase it may be disregarded. Although theoretically this curve should be as complex as the disappearance curve that was obtained from blood, its contour in every instance approximated that of a simple exponential func- 


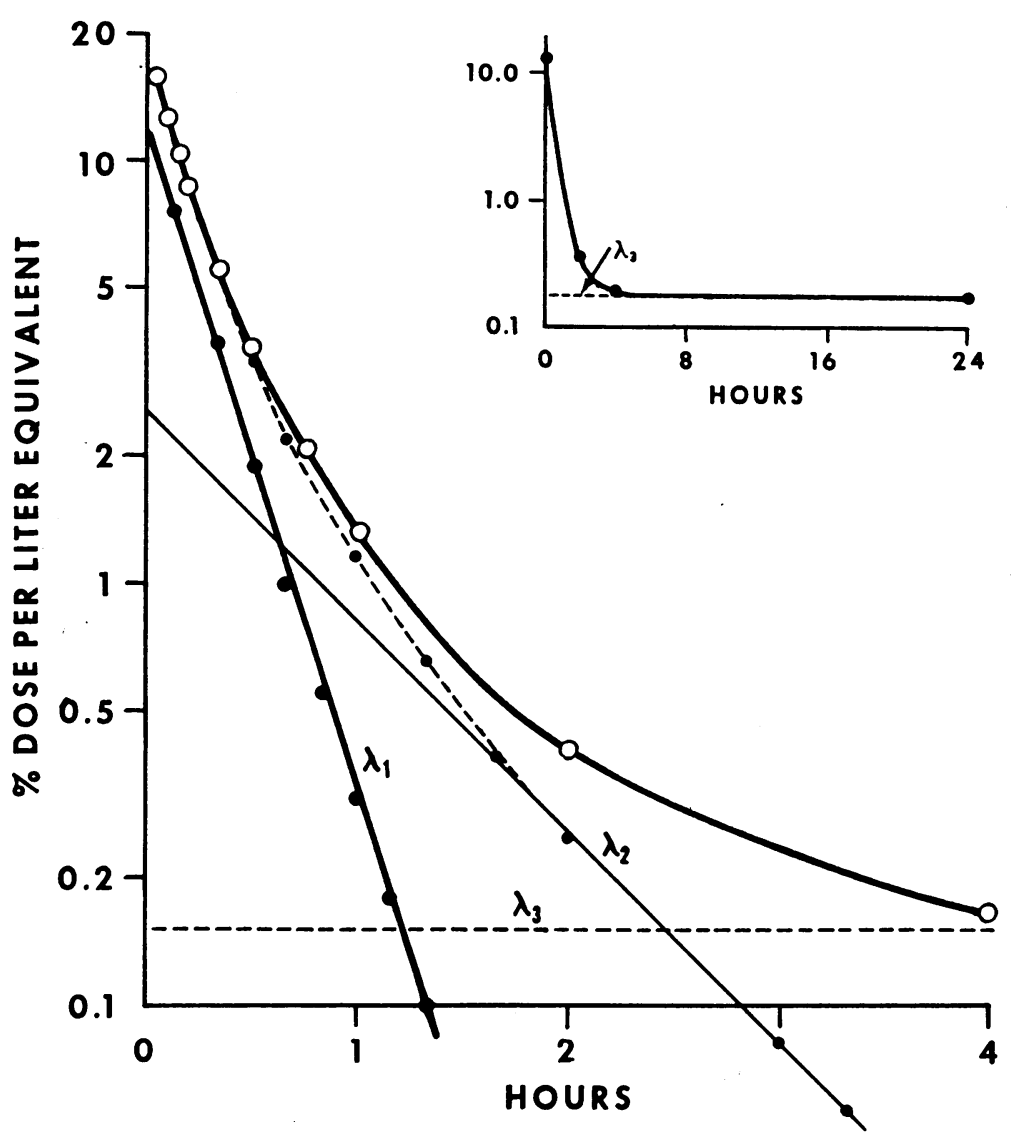

Fig. 3. Curve analysis, erythrocytes, mean of eight control subJECTS. The point midway between the beginning and end of the injection was taken as zero time. A correction for the free blood pool at zero time was not attempted, but its magnitude appeared to be less than $10 \%$ of the plateau value. In the curve analysis $\lambda_{3}$ is observed directly as the terminal slope of the curve. When this terminal phase is extrapolated to zero time and the extrapolated portion substracted from the original curve, a twocomponent curve remains with terminal slope $\lambda_{2}$. Likewise subtraction of this extrapolated terminal portion from the two-component curve gives a final single component of slope $\lambda_{1}$. Slopes, expressed as fraction per minute, are : $\lambda_{1}=0.063 ; \lambda_{2}=0.019 ; \lambda_{s}=0.0001$.

tion. In other words, a straight line of slope $\lambda_{s}$ representing the rate constant of a simple growth equation could be obtained by subtracting observed points from the value of the asymptotic limit. This is not surprising because $\lambda_{1}$ is the dominant slope of the blood curve during the first hour, and as will be explained later, the slope $\lambda_{s}$ obtained over the spleen should be the same as $\lambda_{1}$ obtained from blood. In instances where blood and spleen counts were obtained in the same patients, the rate constant $\left(\lambda_{s}\right)$ from the spleen curve did, in fact, approximate $\lambda_{1}$ from the blood curve. Actual mean values for eight control subjects in which both measurements were made were 0.06 for $\lambda_{1}$ and 0.07 for $\lambda_{s}$. In all tabulations that follow, $\lambda_{s}$ was employed exclusively because, for reasons previously stated, its graphic derivation was considered to be more accurate.

Values of $\lambda_{8}$ for all subjects are presented in Table I. The mean rate is higher in the group with splenomegaly than in control subjects. The value of $p$ is 0.01 .

The shape of the uptake curves over the liver differed markedly from those over the spleen. An abrupt rise accompanied the injection of labeled cells. This rapid rise ceased within less than 
a minute after completion of the injection, after which a near-plateau was established. During the succeeding hour only a slow slight increase usually was apparent. The flatness of the curve after 1 minute could be appreciated by comparing its height at the two extremes. In the control subjects the amplitude at 1 minute averaged $85 \%$ of that at 1 hour. The immediate abrupt rise of the hepatic curve most certainly could be ascribed to initial influx of labeled cells into the organ. Thereafter apparently the increase in concentration of trapped cells barely exceeded the disappearance rate of labeled cells in free flowing hepatic blood within which the cell population was identical to that of systemic blood. It was possible to correct the portion of the hepatic curves between 1 and 60 minutes for the substantial loss of activity in circulating blood by employing a ratio derived from the decrement measured in venous blood at successive intervals during this time. The rate constant of the accumulation curve so derived approximated the $\lambda_{1}$ obtained for blood. The reason for a correspondence between the rate constants of blood, spleen, and liver will be presented in the discussion.

Hepatic activity at 1 hour in 11 subjects with normal sized spleens averaged approximately $15 \%$ of that over the spleen (Table I). The range was 8 to $35 \%$. Corresponding values in six patients with cirrhosis and splenomegaly were approximately $9 \%$, with a range of 6 to $12 \%(p=0.02)$. In other words the spleen count was approximately 6 times that of liver in the controls and 10 times that of liver in patients with splenomegaly. This is consistent either with an increase in sequestration by spleen or decrease in sequestration by liver. A spleen to liver ratio, however, is not proportional to that of the actual total activity in the two organs. A relatively narrow collimation will view a smaller proportion of total liver than of total spleen. Moreover, the deep portions of the liver will be counted less efficiently than the deepest re-

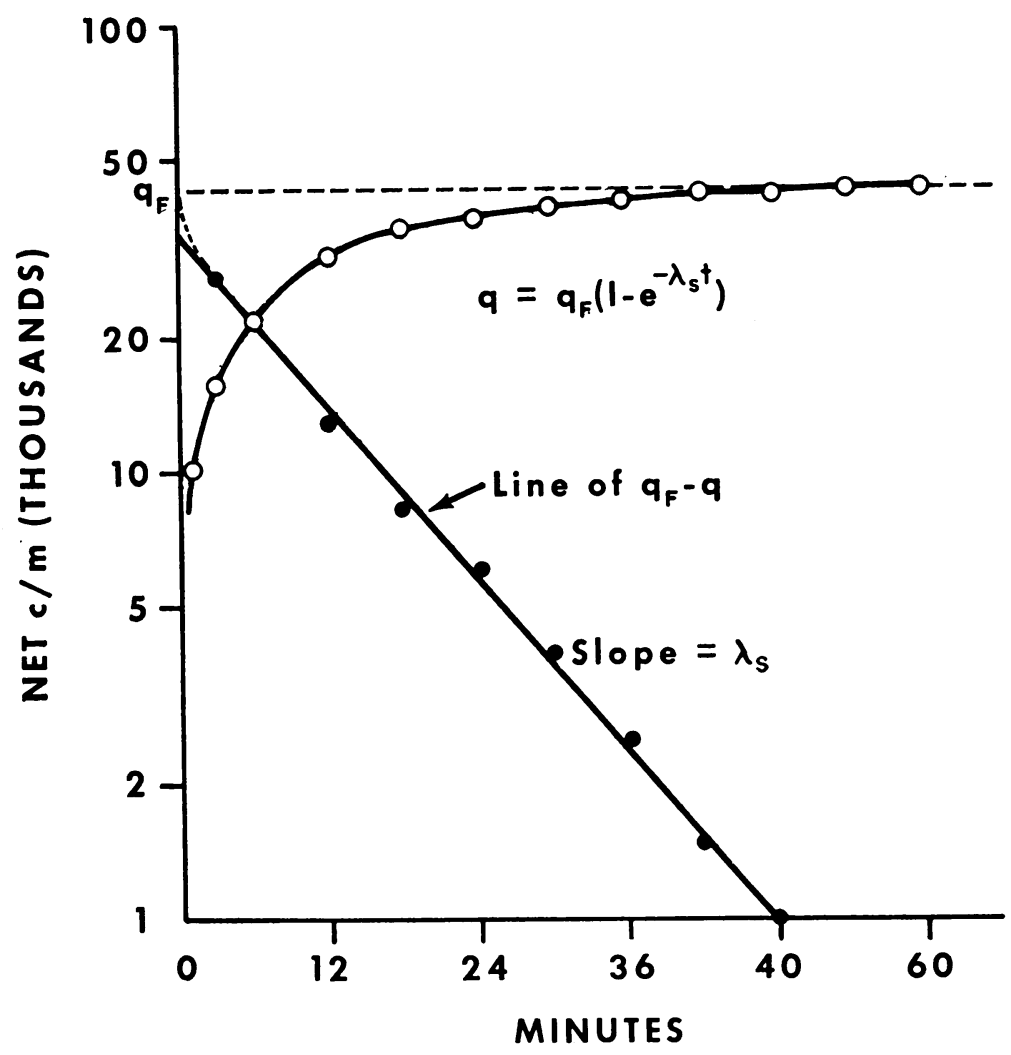

Fig. 4. Curve obtained by direct SPLeEn count. Observed values at time $t$ are $q$ (open circles). The asymptotic limit is $q_{F}$. The rate constant $\lambda_{s}$ is the slope of the line derived by subtraction (solid circles). 
TABLE I

Miscellaneous observations, controls and cirrhosis

\begin{tabular}{|c|c|c|c|c|c|}
\hline Diagnosis & $\begin{array}{l}\text { Spleen } \\
\text { scan } \\
\text { area }\end{array}$ & $\begin{array}{l}\text { Splenic } \\
\text { pulp } \\
\text { pressure }\end{array}$ & $\begin{array}{l}\text { Uptake rate } \\
\left(\lambda_{\theta}\right)\end{array}$ & $\frac{(\text { Liver count })(100) *}{\text { Spleen count }}$ & \\
\hline & $\mathrm{cm}^{2}$ & $m m$ water & & & \multirow{20}{*}{$\begin{array}{l}\text { Normal size } \\
\text { spleen } \\
\left(<90 \mathrm{~cm}^{2}\right)\end{array}$} \\
\hline Control & 80 & 170 & 0.079 & 20.3 & \\
\hline Control & 87 & 265 & 0.083 & 6.5 & \\
\hline Control & 56 & 210 & 0.051 & 15.2 & \\
\hline Control & 77 & & 0.072 & 8.1 & \\
\hline Control & 56 & & 0.053 & 35.0 & \\
\hline Control & 64 & & 0.061 & 9.3 & \\
\hline Control & & & & 11.5 & \\
\hline Control & 87 & 165 & 0.112 & 12.3 & \\
\hline Control & 87 & & 0.067 & 14.2 & \\
\hline Control & 70 & & 0.066 & & \\
\hline Control & 65 & & 0.049 & & \\
\hline Control & 65 & & 0.084 & & \\
\hline Control & 57 & & 0.042 & & \\
\hline Cirrhosis & 49 & 235 & 0.070 & 5.3 & \\
\hline Cirrhosis & 80 & 155 & 0.110 & 23.8 & \\
\hline Cirrhosis & 85 & 310 & 0.080 & & \\
\hline Cirrhosis & 79 & 255 & 0.084 & & \\
\hline Cirrhosis & 77 & 285 & 0.072 & & \\
\hline Cirrhosis & 86 & 280 & 0.122 & & \\
\hline \multicolumn{3}{|l|}{ Mean $\pm \mathrm{SE}$} & $0.074 \pm 0.0048$ & $14.7 \pm 2.6$ & \multirow{14}{*}{$\begin{array}{l}\text { Large spleen } \\
\left(>90 \mathrm{~cm}^{2}\right)\end{array}$} \\
\hline Cirrhosis & 96 & 340 & 0.044 & 7.5 & \\
\hline Cirrhosis & 99 & 450 & 0.105 & 11.0 & \\
\hline Cirrhosis & 100 & 265 & 0.063 & 6.1 & \\
\hline Cirrhosis & 123 & & 0.064 & 6.1 & \\
\hline Cirrhosis & 153 & 375 & 0.080 & \multirow{9}{*}{$\begin{array}{l}11.9 \\
10.8\end{array}$} & \\
\hline Cirrhosis & 94 & 222 & 0.136 & & \\
\hline Cirrhosis & 222 & 280 & 0.139 & & \\
\hline Cirrhosis & 162 & 375 & 0.160 & & \\
\hline Cirrhosis & 136 & & 0.122 & & \\
\hline Cirrhosis & 92 & 610 & 0.157 & & \\
\hline Cirrhosis & 131 & 365 & 0.110 & & \\
\hline Cirrhosis & 152 & 355 & 0.096 & & \\
\hline Cirrhosis & 260 & 445 & 0.173 & & \\
\hline Mean $\pm \mathrm{SE}$ & & & $0.106 \pm 0.012$ & $8.9 \pm 0.98$ & \\
\hline
\end{tabular}

* At 60 minutes.

gions of the spleen because of the effects of both distance and tissue absorption. Thus a spleen to liver ratio of $6: 1$ by surface count does not denote the existence of an identical ratio for total content. On the other hand, the difference in ratio between the two groups of subjects undoubtedly has meaning. Splenomegaly, by pure change in geometry alone, should result in a lowering of the count rather than an increase because a smaller fraction of the total organ is under the collimator. It is therefore reasonable to conclude that the proportion of labeled altered cells in the spleen is greater in the patients with cirrhosis and splenomegaly than in control subjects.

Correlations. From Figure 5A it again is apparent that the rate of uptake $\left(\lambda_{s}\right)$ is substantially higher in patients with cirrhosis than in control subjects. Both this figure and Table II indicate that a positive correlation exists between spleen size and rate of uptake. On the other hand, pressure and rate of uptake correlate poorly.

Even though an attempt was made to control the corpuscular variable by making the cells maximally susceptible to sequestration, and therefore relatively uniform in this respect, some variation in cells as reflected by osmotic fragility would be expected. That such variation does exist and that the degree of fragility of the heated cells is positively correlated with rate of removal from blood is apparent from Figure 5B and Table II. This might raise the question whether some unexpected red cell component were operating to contribute toward the correlation observed between rate of removal and spleen size. If this were true, a 


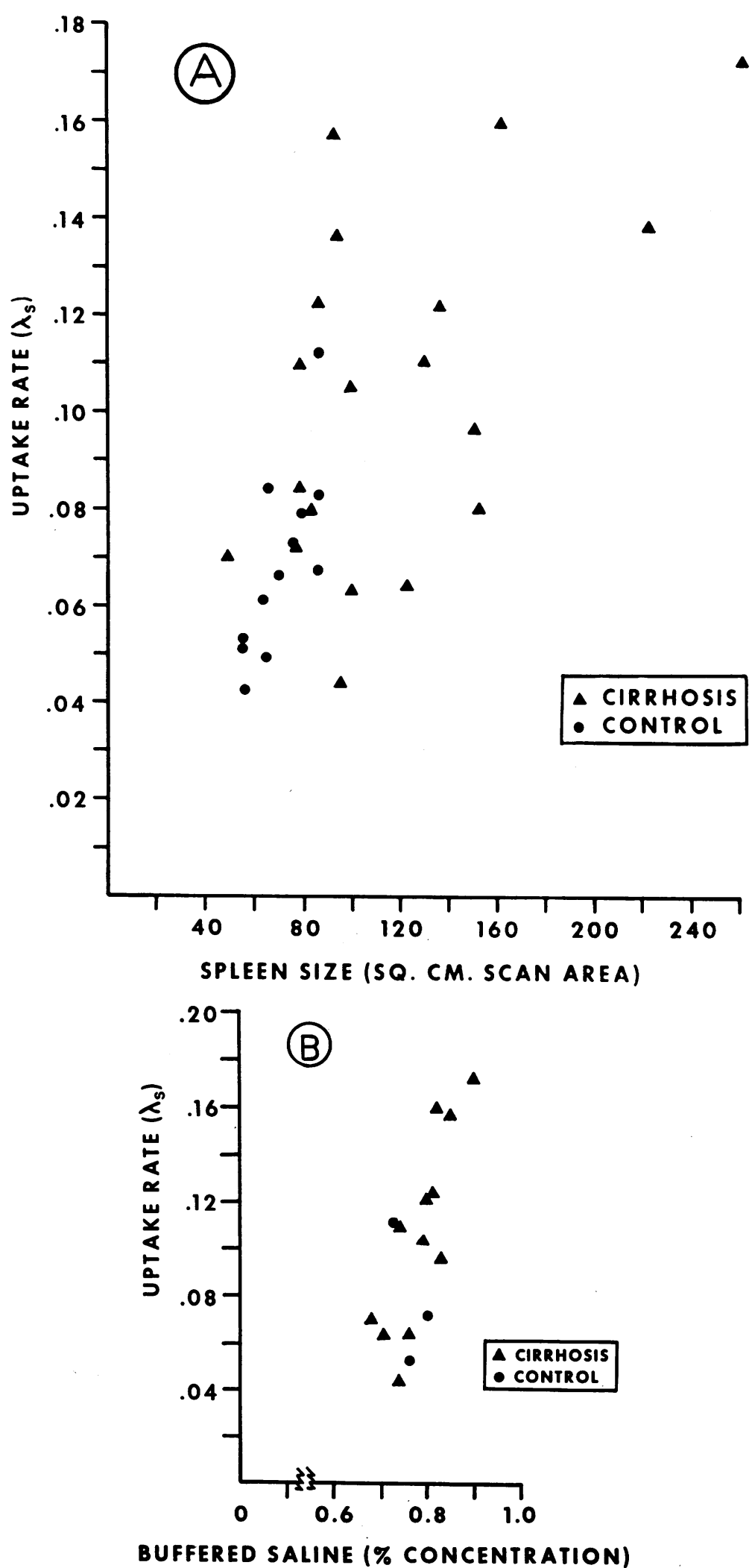

Fig. 5. Correlation plots. A. Spleen size vs. rate OF UPTAKE $\left(\lambda_{s}\right)$. B. OSMOTIC FRAGILITY AFTER HEATING vS. RATE $\left(\lambda_{s}\right)$. 
TABLE II

Correlations obtained by two methods of computation

\begin{tabular}{|c|c|c|c|c|c|}
\hline & \multirow{2}{*}{$\begin{array}{l}\text { No. of } \\
\text { cases }\end{array}$} & \multicolumn{2}{|c|}{$\begin{array}{l}\text { Pearson's } \\
\text { coefficient }\end{array}$} & \multicolumn{2}{|c|}{$\begin{array}{l}\text { Spearman's } \\
\text { rank corre- } \\
\text { lation }\end{array}$} \\
\hline & & $r$ & $p^{*}$ & $r_{s}$ & $p^{*}$ \\
\hline Size vs. rate & 32 & 0.67 & 0.001 & 0.96 & 0.001 \\
\hline Pressure vs. rate & 21 & 0.39 & 0.08 & 0.32 & 0.16 \\
\hline Size vs. pressure & 21 & 0.41 & 0.07 & 0.63 & 0.003 \\
\hline Osmotic fragility & & & & & \\
\hline $\begin{array}{l}\text { vs. rate } \\
\text { Osmotic fragility }\end{array}$ & 15 & 0.73 & 0.003 & 0.66 & 0.008 \\
\hline vs. size $\dagger$ & 30 & -0.22 & 0.25 & 0.17 & 0.38 \\
\hline
\end{tabular}

* The probability as expressed by $\mathrm{p}$ was derived from $t$, which in turn was calculated by the formula: $t=r$ (or $r_{s}$ ) $\sqrt{\frac{\mathrm{N}-2 .}{1-\left(r \text { or } r_{s}\right)^{2}}}$

t Further breakdown of series by category, number of cases, mean fragility, and SE of mean as follows: Spleen scan larger than $90 \mathrm{~cm}^{2}, 14,0.76 \pm 0.02$; spleen scan smaller than $90 \mathrm{~cm}^{2}, 16,0.75 \pm 0.01$; total controls, $9,0.75$ \pm 0.01 ; total cirrhosis, $21,0.76 \pm 0.02$.

good correlation between spleen size and osmotic fragility should be demonstrable. Such is not the case (Table II).

Disorders other than cirrhosis. The findings in five patients with miscellaneous disorders are presented in Table III. Although the group is small and nonhomogeneous, a trend toward rapid rate of removal with increasing spleen size is readily apparent. As was the case with splenomegaly in cirrhosis, this relationship seems not to be related to a systematic difference in osmotic fragility of the heated cells.

\section{Discussion}

Determination of rate of disposal of material from blood by measurement of accumulation of tracer in a recipient reservoir was described by Keating, Power, Berkson, and Haines (12) for $\mathrm{I}^{131}$ taken up by the thyroid gland and for the

TABLE III

Miscellaneous disorders other than cirrhosis

\begin{tabular}{lccc}
\hline \multicolumn{1}{c}{ Diagnosis } & $\begin{array}{c}\text { Size of } \\
\text { spleen } \\
\text { scan }\end{array}$ & $\begin{array}{c}\text { Uptake } \\
\text { rate }\end{array}$ & $\begin{array}{c}\text { Osmotic } \\
\text { fragility } \\
\text { (post- } \\
\text { heat) }\end{array}$ \\
\hline & $\mathrm{cm}^{2}$ & $\left(\lambda_{8}\right)$ & \\
Splenomegaly, cause unknown & 280 & 0.29 & 0.68 \\
Lymphosarcoma & 272 & 0.17 & 0.80 \\
Homozygous Hb c disease & 207 & 0.13 & 0.90 \\
Chronic lymphocytic leukemia & 136 & 0.11 & 0.76 \\
Hereditary spherocytosis & 68 & 0.06 & 0.82 \\
\hline
\end{tabular}

component excreted in urine. Hughes Jones, Mollison, and Veall (13) applied a similar method to the uptake of $\mathrm{Cr}^{51}$-labeled incompatible cells by the spleen, and Harris, McAlister, and Prankerd (14) employed it in studies of the splenic uptake of autologous cells. The first two of these groups of investigators pointed out that the exponential rate constant of the accumulation curve of an irreversible receiving reservoir is identical to that of the exponential decay curve of blood. In the present studies the principle component of the blood curve is expressed as $q=q_{o} e^{-\lambda_{1} t}$, whereas the accumulation curve for spleen is $q=q_{F}$ (1$\left.e^{-\lambda_{s} t}\right)$. The rate constants $\lambda_{1}$ and $\lambda_{s}$ should theoretically be identical. Both represent fractional rate of loss from blood. They are assigned separate symbols only because they are derived from independent measurements. A rate constant of accumulation over the liver or any other participating organ also should be identical to $\lambda_{1}$. For any one of a number of reservoirs of accumulation it is the fractional rate of loss from blood which is being measured. Only $q_{F}$, the asymptotic limit, will vary. This coefficient is proportional to the fraction of total dose that ultimately reaches the given organ. Because the mathematical proof of the identity of rate constants of accumulation with the rate constant of a blood decay curve is not given in the publications that have been cited, it is desirable to present it here.

Assume a blood pool ( $a$ ) with two avenues of exponential removal with rate constants $\lambda_{b a}$ and $\lambda_{c a}$ for exits to collecting pools $b$ and $c$. Let $\lambda_{b a}+$ $\lambda_{c a}=\lambda$, the over-all rate constant for pool $a$. Let $q$ be the amount of tracer in a given pool at time $t$. For loss from blood pool (a)

$$
\frac{d q_{a}}{d t}=-q_{a} \lambda
$$

Integrate

$$
q_{a}=q_{a o} e^{-\lambda t} \quad\left(\text { at } t=0, q_{a}=q_{a o}\right) .
$$

For pool $b$

$$
\frac{d q_{b}}{d t}=q_{a} \lambda_{b a}=\lambda_{b a}\left(q_{a e} e^{-\lambda t}\right) .
$$

Integrate

$$
q_{b}=\frac{-q_{a o}}{\lambda} \lambda_{b a} e^{-\lambda t}+\text { constant. }
$$


The constant is

$$
\frac{q_{a o} \lambda_{b a}}{\lambda} \quad\left(\text { at } t=0, q_{b}=0\right) .
$$

Thus,

$$
q_{b}=\frac{q_{a o} \lambda_{b a}}{\lambda}\left(1-e^{-\lambda t}\right)
$$

Similarly,

$$
q_{c}=\frac{q_{a a} \lambda_{c a}}{\lambda}\left(1-e^{-\lambda t}\right) \quad\left(\text { at } t=0, q_{c}=0\right) .
$$

The rate constants of both $q_{b}(t)$ and $q_{c}(t)$ are the same as that of blood. The coefficients preceding the parentheses are fractions of total dose ultimately reaching the particular reservoir, and they are proportional to the fractional rate constants $\lambda_{b a}$ and $\lambda_{c a}$. These rate constants, however, do not represent the slopes of these functions. Also, the slope $\lambda$ would not be affected by differences in the proportion of a total recipient organ viewed by a counter placed in a fixed position over a part of the organ.

In the present studies the observation of a highly significant correlation between over-all rate of sequestration, $\lambda_{8}$, and spleen size does not prove that spleen itself is the organ that is responsible for the difference in rate. When this observation is coupled with the finding that surface counts show a higher spleen to liver ratio in the presence of splenomegaly, however, the conclusion seems inescapable that the spleen is responsible. As was pointed out in Results, although this ratio is not an accurate measure of total organ content, a change in ratios should mean a corresponding shift in distribution of total dose between the two organs. With evidence that the total sequestration rate is increased, along with evidence that a relatively higher proportion of total dose is in the spleen, it is fair to conclude that splenic sequestration is increased in the presence of splenomegaly.

Although correlation does not establish causal relationship between size and rate of sequestration, such a relationship becomes increasingly plausible as other factors that might affect rate of cell removal are systematically excluded. A corpuscular variable has been fairly well excluded by deliberately altering the cells to make them maximally susceptible to removal. In such a cir- cumstance the trapping function of the spleen should become the dominant rate-limiting mechanism. The nearly identical mean osmotic fragility of heated cells injected into subjects with spleens exceeding $90 \mathrm{~cm}^{2}$ of scanned area versus that of cells given to subjects with spleens measuring less than $90 \mathrm{~cm}^{2}$ would suggest that corpuscular differences were in fact eliminated, provided that such fragility can be taken as an index of the "cell factor" which determines susceptibility to sequestration.

Whether a trapping function directed toward artificially damaged cells is identical to that operating against a natural spectrum of cells is uncertain. It is conceivable, but rather unlikely, that separate functional mechanisms may exist for the two types of cells. The present design for measurement of rate is not easily applied to labeled unaltered cells from a normal donor because accumulation in the spleen is extremely slow. Asymptote may not be reached even in 30 days. Previously reported studies that have documented the increased rate of disappearance of autologous cells in hepatic cirrhosis have included limited observations on spleen size in relation to red cell survival. Jones, Weinstein, Ettinger, and Capps (3) recorded the presence or absence of splenomegaly as judged by palpation and roentgenographic evaluation. Of eight patients with shortened survival time six had splenomegaly. Of three with normal survival time one had splenomegaly. Although these figures suggest a relationship between splenomegaly and shortened red cell survival, the series is too small to attempt statistical evaluation. Jandl, Greenberg, Yonemoto, and Castle (15) in a case of hepatic cirrhosis with anemia and decreased erythrocyte survival time observed a relatively high uptake of $\mathrm{Cr}^{51}$-labeled autologous cells in the spleen as compared to three normal control subjects. The spleen, however, was not palpable.

A possible direct effect of hemodynamics on sequestration is worthy of comment. If adhesion of erythrocytes to walls of splenic channels is an important mechanism of entrapment, retarded flow through such channels might promote adhesion and thereby in itself favor sequestration regardless of organ size. The finding of a poor correlation between rate of erythrocyte removal and portal pressure suggests that stasis, to the 
extent that it is implied by elevated portal pressure, is not of primary importance. Jandl, Simmons, and Castle (16), in order to evaluate the effect of changes in filtration pressure on the passage of red cells, performed in vitro experiments with a sieve model consisting of a Millipore membrane. They observed that when cells were clumped into agglutinated masses, or into rouleaux arrangements, their passage was impaired to a much greater extent when the pressure gradient was low than when it was high. The passage of dispersed normal cells and sickle cells, on the other hand, was not significantly affected by alterations in pressure. These observations would suggest that to the degree that the spleen functions as a filter increased trapping of cells arranged in clumps would be favored by congestion and reduction in effective filtration pressure; however, cells in the dispersed state would not be influenced by the pressure gradient. Therefore, if we assumed that heat-sphered cells do not clump, an effect of pressure change would not be predicted.

It has already been mentioned that in the curve of uptake over spleen, which is $q=q_{F}\left(1-e^{-\lambda_{s} t}\right)$, the coefficient $q_{F}$ is proportional to the total dose ultimately taken up by the spleen. With the anticipation of measuring this component, an attempt was initially made to determine total accumulation in the spleen by an external count taken after 1 to 2 hours at $50 \mathrm{~cm}$ distance with an attached collimator accepting a circular area $15 \mathrm{~cm}$ in diameter at the surface of the skin. The standard consisted of a sample of the labeled cells. A mean value obtained in 11 control subjects was $56 \%$, but the variation was extreme. The range was 16 to $87 \%$. Calculations from these measurements were not made because of a conviction that problems of variable geometry, tissue absorption, and hepatic overlap would introduce serious inaccuracies. According to Wagner and co-workers (9) the proportion of cells going to the spleen as compared to the liver is affected by the degree of thermal injury. With accurate control of temperature and duration of heating, it seems doubtful that such an inconstancy could be implicated as a cause of the wide variation that was encountered in the estimate of total uptake by external counting. Splenectomy, of course, would provide access to tissue for an accurate. determination of total uptake which, coupled with the rate constant from the curve, would give a numerical value for fractional rate of removal by the spleen alone.

The present findings, although directing attention toward a nonhumoral function of the spleen, nevertheless are in accord with Dameshek's statement that "the greater the increase in splenic tissue the greater usually is the degree of hypersplenism" (17). The results along with previous observations with transfused donor cells $(1,2)$ suggest that even though such parameters as nutritional state, liver function, bleeding, and hypofunction of bone marrow may participate as causes of anemia in cirrhosis, special attention must be directed toward an extracorpuscular hemolytic process. This process may well consist of increased splenic activity resulting from nothing more than an increment in the mass of the organ.

In recent experiments by Jacob, MacDonald, and Jandl (18) enlargement of the spleen in rats given acetylphenylhydrazine was accompanied by reticulum cell hyperplasia within the organ. This cellular reaction was construed to be a response to the increased work of removing the cells altered by the drug. That the hyperplasia of reticular tissue was accompanied by increased function of the spleen was apparent from the increased uptake of test doses of labeled cells altered by $\mathrm{N}$-ethylmaleimide. These findings are compatible with the concept that the sequestration function of the spleen is significantly affected by reticuloendothelial mass and that any mechanism which stimulates reticuloendothelial growth also stimulates sequestration.

\section{Summary}

The rate of removal from blood of thermally damaged red cells in patients with hepatic cirrhosis correlated well with the degree of splenomegaly and poorly with the degree of elevation of portal pressure. An increased spleen to liver ratio of radioactivity by surface count in the presence of splenomegaly suggested that sequestration by the spleen was responsible for the increased rate of removal of cells. Rate of sequestration was increased also in patients with splenomegaly due to causes other than cirrhosis.

These findings support the concept that increased spleen size in itself can result in hyper- 
function. The observations also suggest that splenomegaly increases sequestration rate regardless of the underlying cause of the splenomegaly.

\section{Acknowledgments}

We are indebted to Dr. Jerry S. Wolkoff for performing the measurements of splenic pulp pressure and to Lida Claire LeBlanc Gamon for the determinations of osmotic fragility.

\section{References}

1. Chaplin, H., Jr., and P. L. Mollison. Red cell lifespan in nephritis and in hepatic cirrhosis. Clin. Sci. 1953, 12, 351.

2. Jandl, J. H. The anemia of liver disease: observations on its mechanism. J. clin. Invest. 1955, 34, 390.

3. Jones, P. N., I. M. Weinstein, R. H. Ettinger, and R. B. Capps. Decreased red cell survival associated with liver disease. Use of radioactive sodium chromate in measurement of red cell survival. Arch. intern. Med. 1955, 95, 93.

f. Allen, F. A., M. H. Carr, and A. P. Klotz. Decreased red blood cell-survival time in patients with portal cirrhosis. Correlation of laboratory and clinical findings. J. Amer. med. Ass. 1957, 164, 955.

5. Hall, C. A. Erythrocyte dynamics in liver disease. Amer. J. Med. 1960, 28, 541.

6. Cawein, M. J. III, A. B. Hagedorn, and C. A. Owen, Jr. Anemia of hepatic disease studied with radiochromium. Gastroenterology 1960, 38, 324.

7. Sheehy, T. W., and A. Berman. The anemia of cirrhosis. J. Lab. clin. Med. 1960, 56, 72.
8. Holzbach, R. T., R. E. Clark, R. A. Shipley, W. B. Kent III, and G. E. Lindsay. Evaluation of spleen size by radioactive scanning. J. Lab. clin. Med. 1962, 60, 902.

9. Wagner, H. N., Jr., M. A. Razzak, R. A. Gaertner, W. P. Caine, Jr., and O. T. Feagin. Removal of erythrocytes from the circulation. Arch. intern. Med. 1962, 110, 90.

10. Atkinson, M., and S. Sherlock. Intrasplenic pressure as an index of portal venous pressure. Lancet 1954, 1, 1325.

11. Parpart, A. K., P. B. Lorenz, E. R. Parpart, J. R. Gregg, and A. M. Chase. The osmotic resistance (fragility) of human red cells. J. clin. Invest. 1947, 26, 636.

12. Keating, F. R., Jr., M. H. Power, J. Berkson, and S. F. Haines. The urinary excretion of radioiodine in the various thyroid states. J. clin. Invest. 1947, 26, 1138.

13. Hughes Jones, N. C., P. L. Mollison, and N. Vea!.. Removal of incompatible red cells by the spleen. Brit. J. Haemat. 1957, 3, 125.

14. Harris, I. M., J. McAlister, and T. A. J. Prankerd. Splenomegaly and the circulating red cell. Brit. 3. Ilacmat. $1456,4,97$.

15. Jandl, J. H., M. S. Greenberg, R. H. Yonemoto, and W. B. Castle. Clinical determination of the sites of red cell sequestration in hemolytic anemias. J. clin. Invest. 1956, 35, 842.

16. Jandl, J. H., R. L. Simmons, and W. B. Castle. Red cell filtration and the pathogenesis of certain hemolytic anemias. Blood 1961, 18, 133.

17. Dameshek, W. Hypersplenism. Bull. N. Y. Acad. Med. 1955, 31, 113.

18. Jacob, H. S., R. A. MacDonald, and J. H. Jand'. Regulation of spleen growth and sequestering function. J. clin. Invest. 1963, 42, 1476. 